\title{
Delayed traumatic spinal epidural hematoma with neurological deficits
}

\author{
Hematoma epidural pós-traumático tardio com evolução para déficit neurológico
}

\author{
Luciano Miller Reis Rodrigues ${ }^{1}$, Felipe Abreu ${ }^{2}$, Edison Noboru Fujiki ${ }^{3}$, Carlo Milani ${ }^{4}$
}

\begin{abstract}
To describe the mechanism that causes spinal epidural hematoma with neurologic deficit and review the literature. We report a case of a 62-year-old man with post-traumatic epidural hematoma in the cervicothoracic spine, who developed progressive neurological deficit which eventually resulted in complete paralysis below T1. During surgical evacuation significant spine compression due to an organizing hematoma was observed. After surgery, the patient's motor function improved and there was a complete recovery of the neurologic deficit after a rehabilitation program. Conclusion: Epidural hematoma can happen after delayed traumatic event leading to a variable degree of neurologic damage.
\end{abstract}

Keywords: Spine; Hematoma; Spinal cord compression

\section{RESUMO}

Descrever o mecanismo causador de hematoma epidural com déficit neurológico e revisão da literatura. Relata-se caso de paciente com 62 anos, do sexo masculino, com hematoma epidural pós-traumático da coluna cervicotorácica, com desenvolvimento neurológico progressivo, resultando eventualmente em paralisia completa abaixo de T1. Durante o esvaziamento cirúrgico foi observada compressão significante da coluna vertebral devido ao hematoma em organização. Após cirurgia houve melhora das funções motoras e recuperação completa do déficit neurológico pós-reabilitação. 0 hematoma epidural pode ocorrer tardiamente a eventos traumáticos, levando a lesões neurológicas de graus variados.

Descritores: Coluna vertebral; Hematoma; Compressão da medula espinhal

\section{INTRODUCTION}

Spinal epidural hematoma (SEH) is an uncommon entity that represents an important cause of cord compression.
SEH can arise spontaneously or after trauma, and it is more common in patients with vascular anomalies and coagulation abnormalities ${ }^{(1)}$.

Post-traumatic SEH is relatively uncommon and represents less than 1 to $1.7 \%$ of all spine injuries ${ }^{(2)}$. Treatment usually involves emergency operative decompression, specially when patients develop delayed and neurological symptoms. We report a case of a posttraumatic SEH of the cervical spine in a patient who developed delayed neurological symptoms.

\section{CASE DESCRIPTION}

A 62-year-old male patient who suffered a direct cervical impact when was weightlifting and from that moment on he started to feel significant pain which improved after use of analgesic drugs. However, three weeks after the incident, he began to experience paresthesia of the fourth and fifth fingers and difficulty in opening his hand. At the same time when paresthesia began, he developed a progressive loss of strength in the leg. In two weeks, he developed complete paralysis with loss of sphincters control.

Radiography and computed tomography did not show signs of fracture. Magnetic resonance imaging (MRI) of cervical and thoracic spine was performed (Figures 1A e 1B) and revealed a considerable mass in the posterior spinal canal, causing significant stenosis of the center canal on C7 and T1. The mass characteristics were consistent with large and posterior epidural hematoma. There was no evidence of fracture, soft tissue or any other abnormality. It is important to mention that the patient did not use anticoagulant medicine and had no changes in his coagulogram.

\footnotetext{
Faculdade de Medicina do ABC - FMABC, Santo André (SP), Brazil.

'MD, Faculdade de Medicina do ABC - FMABC, São Paulo (SP), Brazil.

${ }^{2}$ Resident at Faculdade de Medicina do ABC - FMABC, Santo André (SP), Brazil.

${ }^{3}$ PhD, Faculdade de Medicina do ABC - FMABC, Santo André (SP), Brazil.

${ }^{4}$ Full professor at Faculdade de Medicina do ABC - FMABC, Santo André (SP), Brazil.

Corresponding author: Luciano Miller Reis Rodrigues - Rua Tucumã, 199 - Jardim Europa - CEP 01455010 - São Paulo (SP), Brasil - Tel.: 1135964186 - e-mail: luciano.miller@uol.com.br

Received on Jan 6, 2010 - Accepted on Sept 21, 2010
} 


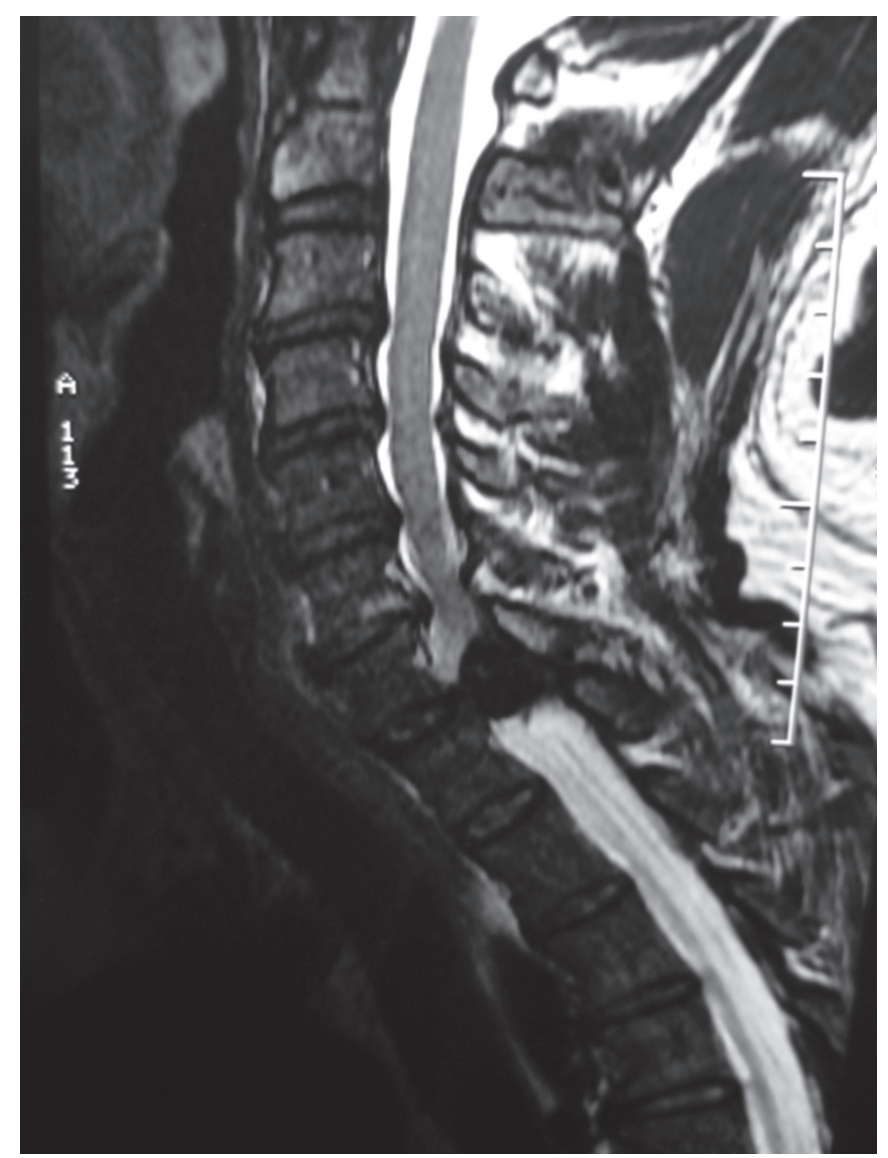

Figure 1A. Sagittal MRI showing posterior epidural hematoma

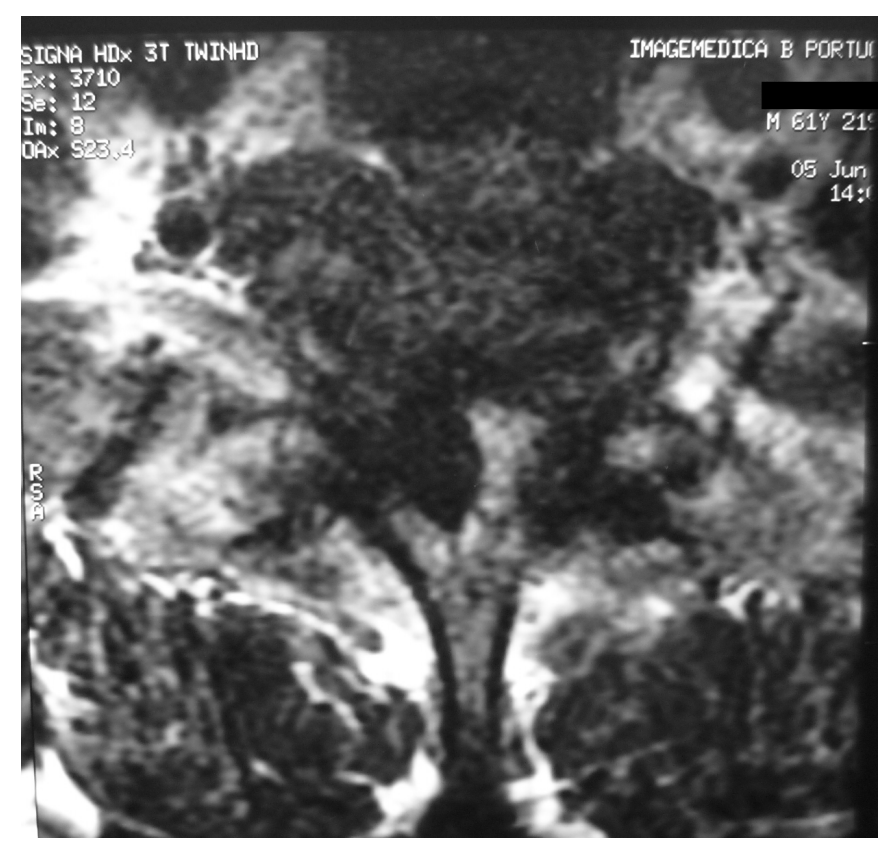

Figure 1B. Axial MRI presented significant compression of bilateral spine

Laminectomy was indicated for the neurological symptoms and the significant spine compression. Surgical findings included substantial compression of hematoma which had a hard consistency. Pathologic examination showed compression caused by the hematoma. The patient demonstrated significant improvement in strength and motor function after surgical decompression, but retained sensory deficit below T4. He also regained partial control of his sphincters.

\section{DISCUSSION}

Traumatic causes of SEH include vertebral fractures, obstetric birth trauma, lumbar punctures, bleeding after surgery, epidural anesthesia and missile injuries ${ }^{(3)}$. In addition, cervical spondylosis, rheumatoid arthritis, Paget's disease, and ankylosing spondylitis are considered risk factors for post-traumatic $\mathrm{SEH}^{(2)}$.

It is quite impossible to determine the causes of bleeding associated withSEH, and the pathophysiological mechanism of SEH remains obscure. Although SEH is rarely originated from the arterial system, the most accepted source is bleeding from ruptures of the valveless venous plexus in the epidural space, which possibly resulted from an abrupt change in venous pressure after blunt trauma ${ }^{(4,5)}$.

Several authors categorize $\mathrm{SEH}$ when associated with minor trauma such as lifting an object or the valsalva maneuver as spontaneous rather than post-traumatic SEH. Particularly in young patients, traumatic SEH may also occur in cases of minor trauma without bone disruption because of the great elasticity of the spine and most likely due to the tearing of epidural veins during acute disc disruption ${ }^{(6)}$.

Spontaneous and traumatic SEH, in most cases, occur dorsally, as observed in this case. This anatomical preference is difficult to explain because of the close adherence to fibrous in posterior longitudinal ligament on the ventral surface of the canal ${ }^{(7)}$.

The symptoms of post-traumatic SEH are generally present immediately after the incident. Posterior evolution of progressive neurological deficit is rare ra, $^{(3,8)}$. Classically, post-traumatic SEH presents as acute painful episodes at the moment of the trauma demonstrating a progressive neurological compromise at the cord a compression level. In this case, the patient developed symptoms of progressive neurological deficit three weeks after the traumatic event.

MRI is the preferred exam to diagnose SEH. CT and plain films of the spine do not evaluate adequately spine when SEH is clinically suggested. Boukobza et al. ${ }^{(9)}$ reviewed MRI characteristics of 11 hematomas and found, after a 24-hour follow-up, that hematomas were usually isointense to the spinal cord on T1-weighted images and heterogeneous on T2-weighted images. The hematoma produces a later high signal intensity in both T1- and T2-weighted images. It is important 
to highlight that magnetic resonance angiography is not a gold standard to spine injuries. However, it may be necessary when a resection vertebral plan in spine tumor is required.

Prompt surgical evacuation of the hematoma with laminectomy has been the most used treatment for patients with persistent symptomatic spinal epidural hematomas with neurological deficits ${ }^{(1,10,11)}$. When patients demonstrate less neurological symptoms, particularly without any progression, and show signs of clinical improvement, corticosteroid treatment with close observation is more appropriate ${ }^{(12)}$. Lawton et al..$^{(13)}$ assessed 30 patients with spinal epidural hematomas and found that neurological deficits improved in $87 \%$ of patients submitted to surgical evacuation of hematomas.

Surgery within the first 12 hours has been correlated to better neurological outcomes. In our case, late spine decompression was performed, resulting in significant improvement of neurological deficits.

Spinal epidural hematomas are uncommon complications after traumatic injuries to the spine. Emergency surgical evacuation should be performed to enable neurological improvement.

\section{REFERENCES}

1. Rechtine GR 2nd, Bolesta MJ, Chrin AM, Louis K. Spontaneous resolution of symptomatic post-traumatic cervical epidural hematoma. J Bone Joint Surg Am. 2001;83-A(2):255-8.
2. Cuenca PJ, Tulley EB, Devita D, Stone A. Delayed traumatic spinal epidural hematoma with spontaneous resolution symptoms. J Emerg Med. 2004;27(1):37-41.

3. Lefranc F, David P, Brotchi J, De Witte O. Traumatic epidural hematoma of the cervical spine: magnetic resonance imaging diagnosis and spontaneous resolution: case report. Neurosurgery. 1999;44(2):408-10.

4. Foo D, Rossier AB. Preoperative neurological status in predicting surgical outcome of spinal epidural hematomas. Surg Neurol. 1981;15(5):389-401.

5. Beatty RM, Winston KR. Spontaneous cervical epidural hematoma: a consideration of etiology. J Neurosurg. 1984;61(1):143-8.

6. Wittebol MC, Van Veelen CW. Spontaneous spinal epidural hematoma. Clin Neurol Neurosurg. 1984;86(4):265-70.

7. Foo D, Rossier AB. Post-traumatic spinal epidural hematoma. Neurosurgery. 1982;11(1 Pt 1):25-32.

8. Groen RJ, Van Alphen HAM. Operative treatment of spontaneous spinal epidural hematomas: a study of the factors determining postoperative outcome. Neurosurgery. 1996;39(3):494-508.

9. Boukobza M, Guichard JP, Boissonet M, George B, Reizine D, Gelbert F, et al. Spinal epidural haematoma: report of 11 cases and review of the literature. Neuroradiology. 1994;36(6):456-9.

10. Segal DH, Lidov MW, Camins MB. Cervical epidural hematoma after chiropractic manipulation in a healthy young woman: case report. Neurosurgery. 1996;39(5):1043-5.

11. Hentschel S, Woolfenden AR, Fairholm DJ. Resolution of spontaneous spinal epidural hematoma without surgery: report of two cases. Spine. 2001;26(22):E525-7.

12. Jamjoom ZA. Acute spontaneous spinal epidural hematoma: the influence of magnetic resonance imaging on diagnosis and treatment. Surg Neurol. 1996;46(4):345-9.

13. Lawton MT, Porter RW, Heiserman JE, Jacobowitz R, Sonntag VK, Dickman CA. Surgical management of spinal epidural hematoma: relationship between surgical timing and neurological outcome. J Neurosurg. 1995;83(1):1-7. Peratio 